\title{
Changes in particulate matter physical properties during Saharan advections over Rome (Italy): a four-year study, 2001-2004
}

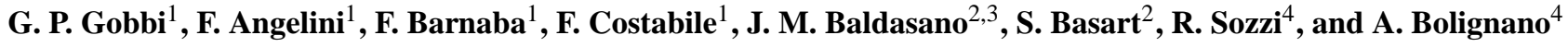 \\ ${ }^{1}$ Institute of Atmospheric Sciences and Climate, ISAC-CNR, Rome, Italy \\ ${ }^{2}$ Barcelona Supercomputing Centre - Centro Nacional de Supercomputación (BSC-CNS), Barcelona, Spain \\ ${ }^{3}$ Environmental Modelling Laboratory, Technical University of Catalonia, Barcelona, Spain \\ ${ }^{4}$ Latium Environmental Protection Agency (ARPA Lazio), Rome, Italy
}

Correspondence to: G. P. Gobbi (g.gobbi@isac.cnr.it)

Received: 31 December 2012 - Published in Atmos. Chem. Phys. Discuss.: 20 February 2013

Revised: 28 May 2013 - Accepted: 17 June 2013 - Published: 1 August 2013

\begin{abstract}
Particulate matter mass concentrations measured in the city of Rome (Italy) in the period 2001-2004 have been cross-analysed with concurrent Saharan dust advection events to infer the impact these natural episodes bear on the standard air quality parameter $\mathrm{PM}_{10}$ observed at two city stations and at one regional background station. Natural events such as Saharan dust advections are associated with a definite health risk. At the same time, the Directive 2008/50/EC allows subtraction of PM exceedances caused by natural contributions from statistics used to determine air quality of EU sites. In this respect, it is important to detect and characterise such advections by means of reliable, operational techniques. To assess the $\mathrm{PM}_{10}$ increase we used both the "regionalbackground method" suggested by EC Guidelines and a "local background" method, demonstrated to be most suited to this central Mediterranean region. In terms of exceedances, the two approaches provided results within $\sim 20 \%$ of each other at background sites, and at $\sim 50 \%$ of each other in traffic conditions.

The sequence of Saharan advections over the city has been either detected by Polarization Lidar (laser radar) observations or forecast by the operational numerical regional mineral dust model BSC-DREAM8b of the Barcelona Supercomputing Centre. Lidar observations were also employed to retrieve the average physical properties of the dust clouds as a function of height. Over the four-year period, Lidar measurements (703 evenly distributed days) revealed Saharan plumes transits over Rome on $28.6 \%$ of the days, with minimum occurrence in wintertime. Dust was observed to reach the ground on $17.5 \%$ of the days totalling 88 episodes. Most (90\%) of these advections lasted up to 5 days, averag-
\end{abstract}

ing to $\sim 3$ days. Median time lag between advections was 7 days. Typical altitude range of the dust plumes was 0-6 km, with the centre of mass at $\sim 3 \mathrm{~km}$ a.g.l. BSC-DREAM $8 \mathrm{~b}$ model simulations (1461 days) predicted Lidar detectable (532 nm extinction coefficient $>0.005 \mathrm{~km}^{-1}$ ) dust advections on $25.9 \%$ of the days, with ground contacts on $13 \%$ of the days. As in the Lidar case, the average dust centre of mass was forecast at $\sim 3 \mathrm{~km}$. Along the 703 day Lidar dataset, model forecast and Lidar detection of the presence of dust coincided on $80 \%$ of the cases, $92 \%$ coincidences are found within a \pm 1 day window.

Combination of the BSC-DREAM8b and Lidar records leads to about $21 \%$ of the days being affected by presence of Saharan dust at the ground. This combined dataset has been used to compute the increase in PM with respect to dust-unaffected previous days. This analysis has shown Saharan dust events to exert a meaningful impact on the $\mathrm{PM}_{10}$ records, causing average increases of the order of $11.9 \mu \mathrm{g} \mathrm{m}^{-3}$. Conversely, $\mathrm{PM}_{10}$ increases computed relying only on the Lidar detections (i.e., presence of dust layers actually observed) were of the order of $15.6 \mu \mathrm{g} \mathrm{m}^{-3}$. Both analyses indicate the annual average contribution of dust advections to the city $\mathrm{PM}_{10}$ mass concentrations to be of the order of $2.35 \mu \mathrm{g} \mathrm{m}^{-3}$. The number of exceedances attributable to Saharan advections at the three station types addressed in this study (urban traffic, urban background and regional background) were found to be $25 \%, 30 \%$ and $43 \%$, respectively. These results confirm Saharan advections in the central Mediterranean as important modulators of $\mathrm{PM}_{10}$ loads and exceedances. 


\section{Introduction}

Mass concentration $\left(\mu \mathrm{g} \mathrm{m}^{-3}\right)$ of particulate matter smaller than 10 micrometers in aerodynamic diameter $\left(\mathrm{PM}_{10}\right)$ is one of the parameters widely employed to assess air quality. In this respect, the current European Union (EU) air quality directive 2008/50/EC (EC, 2008) allows no more than 35 exceedances per year of the daily average threshold of $50 \mu \mathrm{g} \mathrm{m}^{-3}$. At the same time, the $\mathrm{PM}_{10}$ yearly average should not exceed $40 \mu \mathrm{g} \mathrm{m}^{-3}$. Considering the high levels of $\mathrm{PM}_{10}$ observed in the largest European cities and the sometimes high values of background $\mathrm{PM}_{10}$ levels (e.g., Putaud et al., 2004; Yttri and Aas, 2006; Querol et al., 2009a; Mol et al., 2011), these limits might result as rather stringent. The directive 2008/50/EC also allows for subtraction of the natural aerosol contributions to the monitored $\mathrm{PM}_{10}$ levels after assessing their origin and amount. Methods to implement such an assessment are summarised in the EC Guidelines on the quantification of the contribution of natural sources under the EU Air Quality Directive 2008/50/EC (EC, 2011). Since at certain times and locations natural aerosol sources can be rather strong, it is important to create effective tools to evaluate such contributions to PM levels.

In Mediterranean Europe the natural phenomenon which mostly affects PM concentrations is the frequent transport of large quantities of mineral dust from the nearby Sahara desert (e.g., Moulin et al., 1998; Rodriguez et al., 2001; Barnaba and Gobbi, 2004; Mitsakou et al., 2008; Querol et al., 2009b; Basart et al., 2012a; Pay et al., 2012). In the central and western Mediterranean such outflow of mineral dust reaches its maximum between Spring and Autumn, while minimising in winter (e.g., Barnaba and Gobbi, 2004; Basart et al., 2009; Pey et al., 2013). In the year 2001, satellite observations showed Saharan dust advections to affect an average $26 \%$ of the central Mediterranean surface area (Barnaba and Gobbi, 2004). In that year, Saharan dust advections observed in Rome by our polarization Lidar extended typically from ground up to $6 \mathrm{~km}$ a.s.l. (Gobbi et al., 2004a), and were estimated to increase the urban $\mathrm{PM}_{10}$ loads by an average $19 \pm$ $15 \mu \mathrm{g} \mathrm{m}^{-3}$ (Gobbi et al., 2007). These advections were observed to originate mostly from the desert regions of southern Tunisia and to bear negative health effects on the city population (Mallone et al., 2011).

On a yearly basis, the Saharan emissions transported to the Mediterranean coasts increase the local $\mathrm{PM}_{10}$ loads by a few $\mu \mathrm{g} \mathrm{m}^{-3}$ (e.g., Pey et al., 2013; Querol et al., 2009b). Single events can however increase the $\mathrm{PM}_{10}$ loads by tens to hundreds $\mu \mathrm{g} \mathrm{m}^{-3}$, potentially affecting the number of exceedances of the EU limits (e.g., Rodriguez et al., 2001; Gobbi et al., 2007; Perrino et al., 2009; Pey et al., 2013). In a quantitative study conducted by particle-induced X-ray emission techniques (PIXE), Nava et al. (2012) found the Saharan advections contribution to $\mathrm{PM}_{10}$ samples collected in Tuscany (central Italy) to range between 3 and $30 \mu \mathrm{g} \mathrm{m}^{-3}$. Such high levels of natural PM loads imply that, at least in the
Mediterranean regions, validated model-based Saharan dust fields should be integrated within regional air quality models to improve the agreement between PM simulations and observations, concurring to disclose the relative contribution of natural vs. anthropogenic sources in the PM records measured at the ground (e.g., Basart et al., 2012a; Carnevale et al., 2012; Pey et al., 2013).

This study provides a characterisation of Saharan advections and an evaluation of their impact on the $\mathrm{PM}_{10}$ mass concentration in the city of Rome, Italy, one of the largest metropolitan areas in Mediterranean Europe. Time and altitude characterisation of the Saharan advection events will be based on model forecasts and polarization Lidar observations, while changes in $\mathrm{PM}_{10}$ concentration will be computed considering average $\mathrm{PM}_{10}$ loads recorded in Rome airquality stations prior and during the dust events. The method to estimate such impact of Saharan dust on $\mathrm{PM}_{10}$ loads will be optimised for the conditions encountered at this central Mediterranean region.

\section{Methods}

To determine the days affected by the presence of Saharan air masses over the city, we employ dust model forecasts and polarization Lidar observations. This section describes the methods employed to measure $\mathrm{PM}_{10}$ (Sect. 2.1), to infer the presence of Saharan advections (2.2 and 2.3) and to determine their contribution to $\mathrm{PM}_{10}$ (2.4).

\section{$2.1 \mathrm{PM}_{10}$ measurements}

The $\mathrm{PM}_{10}$ records utilised here were collected at three stations run by ARPA Lazio, the environmental protection agency in charge of the air quality monitoring in the Latium region. Two of the stations, Magna Grecia $\left(\mathrm{MG}, 41.88^{\circ} \mathrm{N}-\right.$ $12.51^{\circ} \mathrm{E}, 49 \mathrm{~m}$ a.s.1.), and Villa Ada (VA, $41.93^{\circ} \mathrm{N}-12.51^{\circ} \mathrm{E}$, 50 ma.s.l.) are located in central Rome, while the third one is situated at Fontechiari (FC, $41.67^{\circ} \mathrm{N}-13.67^{\circ} \mathrm{E}, 388$ m a.s.l.), about $70 \mathrm{~km} \mathrm{SE}$ of Rome. Stations type can be defined as: "urban traffic" for MG, "urban background" for VA, and "regional background" for FC. $\mathrm{PM}_{10}$ mass concentration was measured by means of Philips Environment MP-101-M, beta-gauge analysers, performing two $\mathrm{PM}_{10}$ average mass readings per hour. After quality check, the readings were averaged to provide the daily mean values employed in our study.

\subsection{The VELIS Lidar}

Polarization Lidar (laser radar) measurements are employed here to detect and characterise Saharan dust events. This Vehicle-Mountable Lidar System (VELIS) was located at the ISAC Rome laboratories $\left(41.84^{\circ} \mathrm{N}-12.65^{\circ} \mathrm{E}, 130 \mathrm{~m}\right.$ a.s.1.), in a semi-rural area approximately $12 \mathrm{~km}$ southeast of the city centre. An extended description of the Lidar system and 
of the relevant data analysis to derive aerosol extinction is given in Gobbi et al. (2004). Here we briefly recall that VELIS employs a frequency-doubled Nd:YAG laser, emitting $532 \mathrm{~nm}$, plane-polarized, $30 \mathrm{~mJ}$ pulses at $10 \mathrm{~Hz}$. Two colocated telescopes allow to collect a full backscatter profile between $\sim 300 \mathrm{~m}$ and $14 \mathrm{~km}$ from the ground, with a vertical resolution of $37.5 \mathrm{~m}$. Overlap correction allows to reconstruct the aerosol profile down to $100 \mathrm{~m}$ a.g.l. Typical averaging time of each profile is $10 \mathrm{~min}$.

Outputs of the VELIS measurement are tropospheric profiles of aerosol backscatter $\beta_{\mathrm{a}}(z)$ and extinction $\sigma_{\mathrm{a}}(z)$ coefficients, plus depolarization ratio $D_{\mathrm{a}}(z)$, all determined at the laser wavelength. The aerosol depolarization $D_{\mathrm{a}}=$ $\left(\beta_{a \perp}\right) /\left(\beta_{a / /}\right)$, i.e., the ratio of the aerosol-induced crosspolarized backscatter signal $\left(\beta_{a \perp}\right)$ to the parallel-polarized one $\left(\beta_{a / /}\right)$ is a good indicator of the shape of the scattering particles (e.g., Sakai et al., 2010). In fact, spherical particles (as liquid aerosols) do not change the polarization plane of the laser beam they backscatter, while non-spherical ones (as dust particles or ice crystals) introduce a marked degree of depolarization. While for continental type aerosols VELIS typically observes depolarization $D_{\mathrm{c}}<10 \%$, in the case of pure Saharan dust close to the source it measured an average depolarization $D_{\mathrm{d}} \sim 41 \%$ (e.g., Gobbi et al., 2000). In Rome, dust advections typically show $15 \%<D_{\mathrm{d}}<30 \%$. In the absence of aerosols, i.e., in pure molecular backscatter, the system measures $D_{\mathrm{m}} \sim 1 \%$. Aerosol depolarization $D_{\mathrm{a}}$ is therefore considered an excellent marker for identifying the presence and altitude of mineral dust over the Lidar station. As in previous analyses, also in this work the vertical distribution of dust during Saharan events is determined as coinciding with regions where $D_{\mathrm{a}}$ increases above $10 \%$. Dust contribution to the extinction is then estimated by weighting the aerosol extinction coefficient by the ratio $D_{\mathrm{a}} / 41 \%$. Since "pure" dust depolarization can happen to be lower than $41 \%$ (e.g., Sakai et al., 2010), this approach provides a lower limit to the retrieved dust extinction coefficient. The VELIS schedule included 2 to 6 profiles per day (depending on sky conditions) collected at non-synchronous times between 07:00 and 21:00 UTC. During the period January 2001-December 2004, the observations covered about $50 \%$ of the days. In particular, VELIS was deployed in field campaigns (and therefore did not operate in Rome) in January 2001, from mid-July to mid-September 2002 (Gobbi et al., 2004b), and during short periods in July 2003 (Tafuro et al., 2006) and August-September 2004 (Barnaba et al., 2007; Highwood et al., 2007). These dates are therefore missing in the present Lidar record. Overall, 703 daily profiles have been employed in this study, with a mean number measurement-days per month of $15 \pm 6$.

\subsection{The BSC-DREAM8b model}

The BSC-DREAM8b model (Nickovic et al., 2001; Pérez et al., 2006a, b; Basart et al., 2012b) simulates the 3- dimensional field of dust concentration in the troposphere and takes into account all major processes of dust life, such as dust emission, horizontal and vertical diffusion and advection and wet and dry deposition. It also includes the effects of the particle-size distribution on aerosol dispersion. The model numerically solves the Euler-type partial differential nonlinear equation for dust mass continuity, and it is fully embedded as one of the governing prognostic equations in the atmospheric NCEP/Eta model.

The main features of BSC-DREAM8b are a source function based on the arid and semi-arid categories of the $1 \mathrm{~km}$ USGS land use dataset, a 8-bin particle size distribution within the $0.1-10 \mu \mathrm{m}$ radius range according to Tegen and Lacis (1996), a source size distribution derived from D'Almeida (1987) and dust radiative feedbacks (Pérez et al., 2006a). In the last years, the model has been used for dust forecasting and as dust research tools in North Africa and the Mediterranean (e.g., Amiridis et al., 2009; Papanastasiou et al., 2010; Marinou et al., 2012). Several evaluation studies outlined the good skills of BSC-DREAM8b concerning both the horizontal and vertical extend of the dust plume in the Mediterranean Basin for a single dust event (Pérez et al., 2006a, b; Haustein et al., 2009; Papanastasiou et al., 2010) and over longer time periods (Kishcha et al., 2007; Pay et al., 2012; Basart et al., 2012b).

The present analysis includes a dust simulation of BSCDREAM8b for the period from 1 January 2001 to 31 December 2004 on an hourly basis. The initial state of dust concentration in the BSCDREAM8b model is defined by the $24 \mathrm{~h}$ forecast from the previous-day model run. The NCEP/FNL Final Operational Global Analysis data at 00:00 UTC are used as initial conditions and boundary conditions at intervals of $6 \mathrm{~h}$. The resolution is set to $1 / 3$ degrees in the horizontal and to 24 layers extending up to approximately $15 \mathrm{~km}$ in the vertical. The domain of simulation covers northern Africa, Middle East and Europe.

The BSC-DREAM8b output analyzed here consists of 1hour time resolution forecasts of dust advections transiting over Rome, so that the entire dataset is made of over 35000 records. The data provided are: dust load, dust concentration and $\mathrm{PM}_{10}$ at the surface, $550 \mathrm{~nm}$ AOD and extinction coefficient at 24 levels (from 86 to $15000 \mathrm{~m}$ a.s.l.). Since these levels are not equally spaced, the values were averaged over a regular, $1 \mathrm{~km}$-thick vertical grid. The dust load, surface concentration and extinction coefficient records from the BSC-DREAM8b model show continuous distributions, with a large occurrence of small, but non-null, values. For this reason, these time series show "absolute dust-free conditions" to occur in less than $2 \%$ of cases. This makes difficult to perform a direct comparison with the Lidar data. In order to do so a screening process was introduced.

An advection, whatever its altitude, is counted when BSC-DREAM8b simulations predicted the presence over the city of "Lidar detectable" (532 nm Extinction $>0.005 \mathrm{~km}^{-1}$ ) dust clouds. Such a signal corresponds to approximately 
$3 \mu \mathrm{g} \mathrm{m}^{-3}$ of dust. The sensitivity of the VELIS Lidar system has then been taken as a threshold for discriminating the BSC-DREAM8b extinction data between dust and non-dust regimes. Hence, considering a Lidar sensitivity of $0.005 \mathrm{~km}^{-1}$ up to $6 \mathrm{~km}$ and $0.01 \mathrm{~km}^{-1}$ above, have been classified as "dust cases" only those profiles where the average extinction exceeds the Lidar-derived threshold at least in one layer. In such way, a total of 9084 dust layers have been detected in the BSC-DREAM8b record, with a time incidence (days per year) of about $26 \%$.

\subsection{Determining the dust-driven $\mathrm{PM}_{10}$ increase}

Operational evaluation of the $\mathrm{PM}_{10}$ increase due to Saharan advections is commonly performed by subtracting a "background" value from the $\mathrm{PM}_{10}$ load during the dust event. Current EU guidelines (EC, 2011) suggest to calculate such an increase at a regional background station and to use this value for all the $\mathrm{PM}_{10}$ monitoring sites in that region. In this approach, the background is computed by averaging the $\mathrm{PM}_{10}$ load at the regional background station in the 15day period preceding and following the event (EU, 2011). This method was originally developed and optimised for the Iberian Peninsula (Escudero et al., 2007).

In our previous work (Gobbi et al., 2007) we choose to compute background $\mathrm{PM}_{10}$ loads at each station being considered, averaging the background over the 15 day period preceding the event. In this work, the best $\mathrm{PM}_{10}$ averaging period over which to evaluate background conditions has been defined after studying the behaviour of meteorological variables and of $\mathrm{PM}_{10}$ loads at various stations during the $\mathrm{Sa}-$ haran advection events. Our starting assumption being: the best estimate of the dust $\mathrm{PM}_{10}$ component during a Saharan advection should be measured against the $\mathrm{PM}_{10}$ load averaged along the shortest number of days preceding the event at the very same station. Figure 1 reports the daily variation of meteorological and $\mathrm{PM}_{10}$ parameters with respect to their average in the 15 day time span preceding and following all the dust advections encountered in the $4 \mathrm{yr}$ study. Error bars represent the $95 \%$ confidence intervals of such averages. Average variations recorded over each whole Saharan event are reported at time zero, regardless of the actual length of the event (on average 3 days, e.g., Sect. 3.1).

At all stations, PM $_{10}$ mass concentrations (Fig. 1a) follow a rather similar behaviour, showing a systematic increase during the six days preceding the events and a decrease during the five days following it. The same pattern is recorded at urban stations (MG and VA), as well as at the regional background one (FC). Such pattern is found to be anti-correlated with respect to wind (Fig. 1d), and precipitation (Fig. 1f), two meteorological drivers of $\mathrm{PM}_{10}$ concentration. Conversely, it is correlated with respect to pressure (Fig. 1b), temperature (Fig. 1c) and sunshine (Fig. 1e). The picture resulting from such comparison indicates a systematic accumulation of $\mathrm{PM}_{10}$ due to (1) stagnation and low precipitation in the

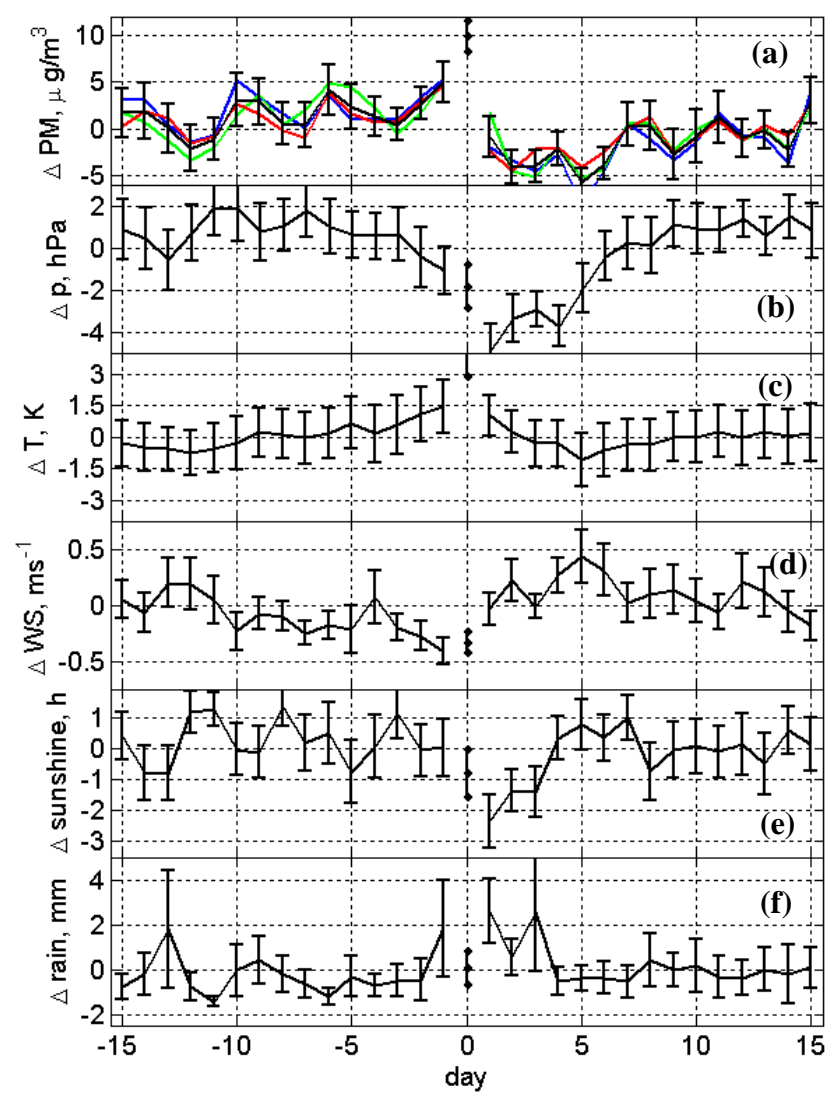

Fig. 1. Average daily variation of $\mathrm{PM}_{10}$ and meteorological parameters with respect to their average in the 15 day time span preceding and following all the dust advections encountered in the $4 \mathrm{yr}$ study. Error bars represent the $95 \%$ confidence intervals of such averages. The average values during the whole Saharan event (whatever its length) are reported at time zero. $\mathrm{PM}_{10}$ curves (a) are reported for MG (blue), VA (green), FC (red) and for the ensemble of the three stations (black). Meteorological parameters considered are: pressure (b), temperature (c), wind speed (d), sunshine (e) and rainfall (f), respectively.

five days preceding the events, (2) increasing wind, precipitation, and temperature, i.e., conditions favouring removal of PM, during the events, and (3) return to pre-advection conditions some 6-8 days past the event.

The previous results also indicate that averaging $\mathrm{PM}_{10}$ over the -15 to +15 dust-free dates across the Saharanflagged date (as the EU guidelines suggest) provides a lower $\mathrm{PM}_{10}$ background than averaging over the 15 days before the events (as done in Gobbi et al., 2007). However, both these approaches include $\mathrm{PM}_{10}$ conditions rather dissimilar from the ones the Saharan events build upon. In particular, employing the data following the event may introduce a bias due to the highly probable presence of rain in the 4 day period across the events. One further parameter to consider is the typical lag between advections. In our case, mean and median time lags between the observed 83 non-wintertime 
advections (out of the total 88 ones) were 9.2 and 7 days, respectively. Choosing longer averaging times may then introduce biases due to contiguous events. Therefore, the 9 day period preceding the events results to be a preferable range to evaluate such background conditions in this central Mediterranean region. In this time span, choice of the averaging length must then be a trade-off between statistical significance and closeness to the event. For these reasons we decided to restrict the averaging period to the 7 days (down to a minimum of 5 days, depending on data availability) preceding each advection event. If available, the full 7 day record is preferable to avoid possible weekly-cycle effects. In fact, the weekly $\mathrm{PM}_{10}$ cycle present at all stations was evaluated to impact results of averaging over five rather than seven days by some $0.5 \mu \mathrm{g} \mathrm{m}^{-3}$ at VA and FC and by at most $1.4 \mu \mathrm{g} \mathrm{m}^{-3}$ at MG.

To support our choice of evaluating Saharan dust loads employing same station background and in-dust $\mathrm{PM}_{10}$ mass concentrations (local approach), we compared dust load estimates made at various sites in the Rome region. In particular, we evaluated the mean bias and root-mean-square (RMS) difference between the dust load estimates performed at the regional background station of Fontechiari (FC) with respect to equivalent estimates performed at the two city stations of VA and MG, and at the two other regional background stations of Allumiere (located some $50 \mathrm{~km} \mathrm{NW}$ of Rome at $500 \mathrm{~m}$ a.s.1.), and of Leonessa (located some $70 \mathrm{~km} \mathrm{NE}$ of Rome at $950 \mathrm{~m}$ a.s.1.). The relevant results are reported in Table 1. In spite of a smaller bias present between background stations, these comparisons show no significant changes in RMS differences and in standard deviations of background or city stations with respect to FC. In this respect, regional background stations do not seem to show with respect to FC a more coherent estimate of dust contribution to $\mathrm{PM}_{10}$ than urban stations do. We interpret this as supporting the local station approach. In this respect, next sections will also show that the estimates performed by the two methods are well within their variability bars. While suffering of the larger variability of PM loads at urban sites (e.g., the daily cycle discussion above), this approach provides additional information about the spatial variability of Saharan dust clouds.

According to Fig. 1, the shorter averaging time employed in this analysis tends to provide a higher value of the background $\mathrm{PM}_{10}$ load with respect to EC (2011), and consequently a lower (by about $2.5 \mu \mathrm{g} \mathrm{m}^{-3}$ in this dataset), more conservative estimate of the increase due to each dust advection. Overall, choice of the averaging time to evaluate "background" $\mathrm{PM}_{10}$ loads is found to be an important condition in the estimate of the increase due to Saharan dust advections. Meteorological parameters as well as other modulators of $\mathrm{PM}_{10}$ loads as the weekly cycle, should definitely be considered in such evaluation process.
Table 1. Bias and RMS differences between dust load estimates $\left(\mu \mathrm{g} \mathrm{m}^{-3}\right)$ performed at the regional background station of Fontechiari (FC) with respect to equivalent estimates performed at the two city stations of VA and MG, and at two other regional background stations (Allumiere, AL, and Leonessa, LE).

\begin{tabular}{lrr}
\hline & Bias $\left(\mu \mathrm{g} \mathrm{m}^{-3}\right)$ & RMS $\left(\mu \mathrm{g} \mathrm{m}^{-3}\right)$ \\
\hline AL-FC & $0.2 \pm 10.0$ & $7.4 \pm 6.7$ \\
LE-FC & $-0.7 \pm 9.7$ & $6.7 \pm 6.9$ \\
VA-FC & $1.3 \pm 11.4$ & $8.9 \pm 7.0$ \\
MG-FC & $5.2 \pm 8.3$ & $8.8 \pm 13.5$ \\
\hline
\end{tabular}

\section{Results}

\subsection{Saharan dust episodes statistics}

The VELIS Lidar dataset consists of 703 measurementdays, of which 197 days with detected Saharan advection. In the same days, BSC-DREAM8b forecasted 248 dust events with extinction coefficient $>0.005 \mathrm{~km}^{-1}(26 \%$ more than VELIS), 158 of which coincide in time with the Lidarobserved ones. Overall, $80 \%$ of the VELIS observations of dust coincide in time with the BSC-DREAM8b forecasts, $92 \%$ fall within one day, and $96 \%$ within 3 days of the BSC-DREAM8b forecasts. Agreement between model and observations on dust presence at the ground was recorded on $70 \%$ of the cases. Season-wise, such agreement shows a minimum in summer $(61 \%)$ while remaining on similar levels $(73-77 \%)$ in the other seasons.

The vertical distribution of the dust layers constitutes an important information in terms of both air quality and climate impacts. Figure 2 depicts the statistics of such parameter ( $1 \mathrm{~km}$ altitude bins) as retrieved by the VELIS Lidar (left column) or modelled by BSC-DREAM8b (right column). Figure $2 \mathrm{a}$ and $\mathrm{b}$ report the frequency of Saharan dust presence in at least one altitude bin. Figure $2 \mathrm{c}$ and d quantify the bin average extinction coefficient $\left(\mathrm{km}^{-1}\right.$ at $\left.532 \mathrm{~nm}\right)$ during such events. Both frequency plots maximize at $2-3 \mathrm{~km}(25 \%$ VELIS and $18 \%$ BSC-DREAM8b). At the ground, VELIS retrieves dust presence on about $17.5 \%$ of the days, while BSC-DREAM $8 b$ forecasts it on $13 \%$. In both the VELIS and BSC-DREAM8b extinction statistics, the centre of mass of the extinction profile is found at approximately $3 \mathrm{~km}$ altitude. It is found from the Lidar record that the altitude seasonal sequence (DJF, MAM, JJA, SON) of this centre of mass is 2.6, $3.2,3.2$ and $2.8 \mathrm{~km}$, respectively.

Average extinction values reported in Fig. $2 \mathrm{~d}$ and e are referred to the overall advections frequency $(28.6 \%)$, regardless of the altitude range of each single event (i.e., for an event occurring at level $\mathrm{X}$ but not at level $\mathrm{Y}$, in the averaging procedure level $\mathrm{Y}$ has a weight of zero). To evaluate the average extinction of Saharan plumes we need to refer to the actual frequency of dust layers at the level addressed (Fig. 2a and $b$ ). The multiplying conversion factors (ratios between 


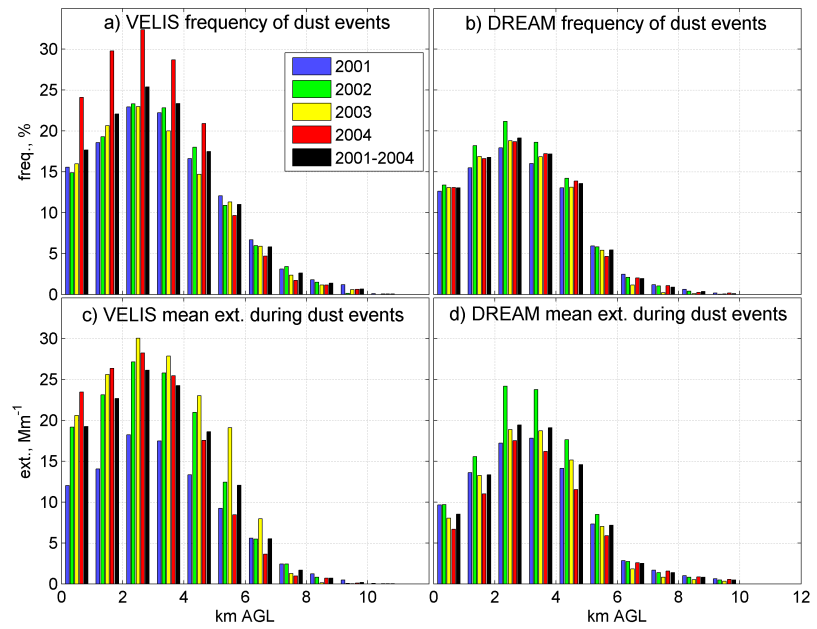

Fig. 2. Vertical distribution of Saharan dust layers properties as observed by VELIS (left column) and forecast by BSC-DREAM8b (right column), respectively: frequency of Saharan dust occurrences at least in one altitude bin (a, b) and average dust extinction coefficient $\left(\mathrm{km}^{-1}\right.$ at $\left.532 \mathrm{~nm}\right)$ per year $(\mathbf{c}, \mathbf{d})$.

the overall advections frequency $(28.6 \%)$ and the altitudedependent frequency of Fig. 2a), allow to obtain the average extinction of Saharan layers as retrieved by VELIS. These indicate typical dust event extinction to be rather constant $\left(0.029 \pm 0.023 \mathrm{~km}^{-1}\right)$ up to $6 \mathrm{~km}$ altitude.

By employing the dust extinction-to-mass conversion of Barnaba and Gobbi (2004) for $2.5 \mathrm{~g} \mathrm{~cm}^{-3}$ density particles, we obtain an extinction to mass ratio of the order of $1.36 \mathrm{~m}^{2} \mathrm{~g}^{-1}$. This factor would lead to an average mass content during the events of the order of $22 \pm 18 \mu \mathrm{g} \mathrm{m}^{-3}$. This is the typical increase in total PM (TSP) expected to occur over the 62 days/year when Saharan advections are observed at the ground level bin by the VELIS Lidar (Fig. 2a). The same computation applied to the BSC-DREAM8b extinction record would lead to an average increase of $12 \mu \mathrm{g} \mathrm{m}^{-3}$. On a yearly basis, the dust contribution to PM (TSP) evaluated by VELIS and BSC-DREAM $8 \mathrm{~b}$ is of 3.9 and $1.6 \mu \mathrm{g} \mathrm{m}^{-3}$, respectively.

On average, the Saharan advections observed by the ISACCNR Lidar over the four-year period lasted 3 days. About $35 \%$ of the events lasted one day and $10 \%$ lasted over 5 days. Only $0.5 \%$ (i.e., once every two years) reached the duration of two weeks.

Table 2 summarises the statistical properties of the dust advections as retrieved by means of VELIS and forecast by BSC-DREAM8b in terms of percent of days in which dust was detected at any level or at ground level, plus average and standard deviation of dust optical depth (532 nm AOD). Overall, the data show that some 100 days per year were affected by Saharan dust transiting over Rome, while dust reached the ground on about 60 days per year. In terms of AOD, the typical optical depth during these Saharan events is
Table 2. Percent of advection days, ground contacts, average $532 \mathrm{~nm}$ optical depth and relevant standard deviation of Saharan dust events as observed by the VELIS Lidar and forecast by BSCDREAM8b.

\begin{tabular}{lccccc}
\hline & 2001 & 2002 & 2003 & 2004 & AVG \\
\hline \% Dust Days & & & & & \\
\hline Lidar & 25.6 & 25.0 & 25.5 & 38.3 & 28.6 \\
BSC-DREAM8b & 25.9 & 26.0 & 24.9 & 26.8 & 25.9 \\
\hline \% Ground Dust & & & & & \\
\hline Lidar & 15.6 & 14.7 & 15.6 & 24.0 & 17.5 \\
BSC-DREAM8b & 12.6 & 13.4 & 13.1 & 13.1 & 13.0 \\
\hline Avg. dust AOD & & & & & \\
\hline Lidar & 0.09 & 0.13 & 0.15 & 0.13 & 0.13 \\
BSC-DREAM8b & 0.08 & 0.10 & 0.08 & 0.07 & 0.08 \\
\hline St.dev.dust AOD & & & & & \\
\hline Lidar & 0.07 & 0.10 & 0.17 & 0.10 & 0.11 \\
BSC-DREAM8b & 0.09 & 0.11 & 0.09 & 0.08 & 0.09 \\
\hline
\end{tabular}

of the order of $0.13 \pm 0.11$. Considering again an average extinction coefficient of $0.03 \mathrm{~km}^{-1}$ this converts (Barnaba and Gobbi, 2004) into an average column load of $96 \pm 81 \mu \mathrm{g} \mathrm{m}^{-2}$ in the VELIS statistics (TSP) and of $59 \pm 66 \mu \mathrm{g} \mathrm{m}^{-2}$ in the BSC-DREAM8b one.

\subsection{The impact of dust on $\mathrm{PM}_{10}$ records}

This analysis is performed using as indicators of dust presence at the ground either the union of the VELIS and the BSC-DREAM8b records or the VELIS record alone. The first choice allows for a safe exclusion of dust-affected days in the computation of non-dust PM loads, while the second fosters a "verified" assessment of dust presence when evaluating the $\mathrm{PM}_{10}$ changes.

Table 3 reports the statistics of $\mathrm{PM}_{10}$ changes observed during dust episodes at the three air quality stations addressed in this work. Observations cover at least $91 \%$ of the 1417 days enclosed in the 2001-2004 period (line 1). Union of the BSC-DREAM8b and VELIS dust records increases the frequency of dust presence at the ground to 20-21\% (line 3 ). The average $\mathrm{PM}_{10}$ levels (line 4) and the number of exceedances of the $50 \mu \mathrm{g} \mathrm{m}^{-3}$ limit (line 7) at the three stations reflect their type. The yearly average increase due to Saharan advections (line 6) ranges between 1.9 and $2.5 \mu \mathrm{g} \mathrm{m}^{-3}$, right within the range estimated by means of the VELIS profiles and BSC-DREAM $8 b$ forecasts. In this respect, it is important to remark that the estimates based on extinction data concern the TSP (total suspended particles) rather than $\mathrm{PM}_{10}$, and that in the presence of Saharan dust in an urban Mediterranean area, $\mathrm{PM}_{10}$ is expected to be of the order of $50 \%$ of TSP (e.g., Querol et al., 2001). After correcting for such a factor, 
Table 3. Four year statistics (2001-2004) of $\mathrm{PM}_{10}$ changes observed during dust episodes at the three air quality stations of Magna Grecia (MG), Villa Ada (VA) and Fontechiari (FC).

\begin{tabular}{|c|c|c|c|c|}
\hline \# & Variable & MG & VA & FC \\
\hline 1 & Observation Days ( $\max 1417)$ & 1320 & 1288 & 1345 \\
\hline 2 & Days with dust at ground (VELIS+BSC-DREAM8b) & 268 & 267 & 287 \\
\hline 3 & \% Days with ground dust (VELIS+BSC-DREAM8b) & 20 & 21 & 21 \\
\hline 4 & Year-Average $\mathrm{PM}_{10}\left(\mu \mathrm{g} \mathrm{m}^{-3}\right)$ & 43.8 & 28.8 & 25.1 \\
\hline 5 & Year-Average $\mathrm{PM}_{10}$ without dust $\left(\mu \mathrm{g} \mathrm{m}^{-3}\right)$ & 41.4 & 26.5 & 23.2 \\
\hline 6 & Year- $\delta \mathrm{PM}_{10}$ in dust $\left(\mu \mathrm{g} \mathrm{m}^{-3}\right)$ & 2.4 & 2.2 & 1.9 \\
\hline 7 & Avg. number of $\mathrm{PM}_{10}$ exceedances $\mathrm{yr}^{-1}$ & 107.0 & 30.9 & 10.0 \\
\hline 8 & $\begin{array}{l}\text { Avg. number of dust-caused } \mathrm{PM}_{10} \text { exceedances } \mathrm{yr}^{-1} \\
\text { (EU Guidelines results in brackets) }\end{array}$ & $\begin{array}{r}27.1 \\
(14.9)\end{array}$ & $\begin{array}{r}9.4 \\
(7.1)\end{array}$ & $\begin{array}{r}4.3 \\
(5.2)\end{array}$ \\
\hline 9 & $\%$ Of dust-caused exceedances & 25 & 30 & 43 \\
\hline 10 & Average $\delta \mathrm{PM}_{10}$ in dust $\left(\mu \mathrm{g} \mathrm{m}^{-3}\right)$ & 13.5 & 10.3 & 9.2 \\
\hline 11 & Standard Deviation $\left(\mu \mathrm{g} \mathrm{m}^{-3}\right)$ & 11.5 & 11.7 & 9.8 \\
\hline 12 & Number of $\delta \mathrm{PM}_{10}<0$ (VELIS+BSC-DREAM8b) & 6 & 6 & 7 \\
\hline 13 & Number of $\delta \mathrm{PM}_{10}<0$ (VELIS) & 0 & 0 & 2 \\
\hline 14 & Average $\delta \mathrm{PM}_{10}$ (VELIS) $\left(\mu \mathrm{g} \mathrm{m}^{-3}\right)$ & 16.4 & 14.7 & 11.0 \\
\hline 15 & Standard Deviation $\left(\mu \mathrm{g} \mathrm{m}^{-3}\right)$ & 9.9 & 12.2 & 10.0 \\
\hline
\end{tabular}

both Lidar-derived mean event load ( $\left.22 \mu \mathrm{g} \mathrm{m}^{-3} \mathrm{TSP}\right)$, and yearly average $\left(3.9 \mu \mathrm{g} \mathrm{m}^{-3} \mathrm{TSP}\right)$ show very good agreement with the results reported at lines 10 and 6 of Table 3 .

Magna Grecia is the site exceeding both the maximum $\mathrm{PM}_{10}$ yearly average $\left(40 \mu \mathrm{g} \mathrm{m}^{-3}\right)$ and number of exceedances (35) established by the EU. Even though Saharan advections are responsible of $26 \%$ of these exceedances (line 9), their subtraction would not reduce the number below the threshold of 35. Conversely, subtracting the dust contribution to yearly $\mathrm{PM}_{10}$ mass brings this average close to the $40 \mu \mathrm{g} \mathrm{m}^{-3}$ limit. The other two sites (VA and FC) do not surpass EU yearly limits. It is however important to notice that between $32 \%$ and $43 \%$ of the exceedances at these locations is attributable to Saharan advections.

Line 8 reports the number of dust-induced exceedances per year obtained according to the present analysis and to the EU guidelines (in brackets). As expected by the meteorological analysis of Sect. 2.4, the number of exceedances at the reference station is larger in the case of EU guidelinesderived data. However, when the city number of exceedances is computed with reference to such rural background station (i.e., according to the EU guidelines) these are lower (7.1\% vs. $9.9 \%$ at VA) and much lower ( $14.9 \%$ vs. $29.3 \%$ at MG) than in our approach. Such mismatch is likely due to a number of processes as: the spatial inhomogeneity of dust loads and of relevant wet and dry removal, traffic resuspension, different dust entrainment between rural and urban boundary layers. Study of these processes is beyond the scope of this paper, but is being addressed within our DIAPASON project (http://www.diapason-life.eu). We however believe all these effects support the use of local stations rather than a single, remote one to evaluate PM loads attributable to dust advection events.
The average $\mathrm{PM}_{10}$ change ascribed to the events of the VELIS+BSC-DREAM8b dataset is reported at line 10 of Table 3. The relevant seasonal frequency distribution of the $\mathrm{PM}_{10}$ change for the two city stations of MG and VA is plotted in Fig. 3. These results show the quite large variability of both event number and dust contributions to $\mathrm{PM}_{10}$ occurring along the year. In particular, they show: (1) maximum loads (of the order of $15 \mu \mathrm{g} \mathrm{m}^{-3}$ ) to occur during the transition seasons, a slightly lower contribution in winter and rather low average loads (of the order of $10 \mu \mathrm{g} \mathrm{m}^{-3}$ ) in summer, and (2) the presence of negative changes, i.e., average $\mathrm{PM}_{10}$ are lower during the events with respect to previous days. While the summertime minimum loads are attributable to a larger dilution allowed by the deeper boundary layer, the latter point is explained by the disappearing of negative loads (Table 3 , line 13 with respect to line 12), when the VELIS record alone is employed to assess the occurrence of dust advection events. Erroneous advections forecast and/or rainout effects are the likely cause of such conditions. In this Lidar framework, $\mathrm{PM}_{10}$ increases per event are 20-40\% larger (Table 3, line 14) while the average yearly increase remains of the order of $2.7 \mu \mathrm{g} \mathrm{m}^{-3}$ due to the lower frequency of the events in this record. Unfortunately, VELIS observations cover only $50 \%$ of the time period and cannot be used for air quality purposes as indicated by the EU Guidelines (EC, 2011).

As mentioned, results in this section were obtained applying the "local background method". This was shown in Sect. 2.4 to be better suited than the "regional background" one to our central Mediterranean region. However, it is worth mentioning that for the regional background station of Fontechiari, use of the two averaging methods brings to estimates of the impact of Saharan dust $\mathrm{PM}_{10}$ loads within $20 \%$ from each other ( 9.2 vs. $10.8 \mu \mathrm{g} \mathrm{m}^{-3}$, respectively). 


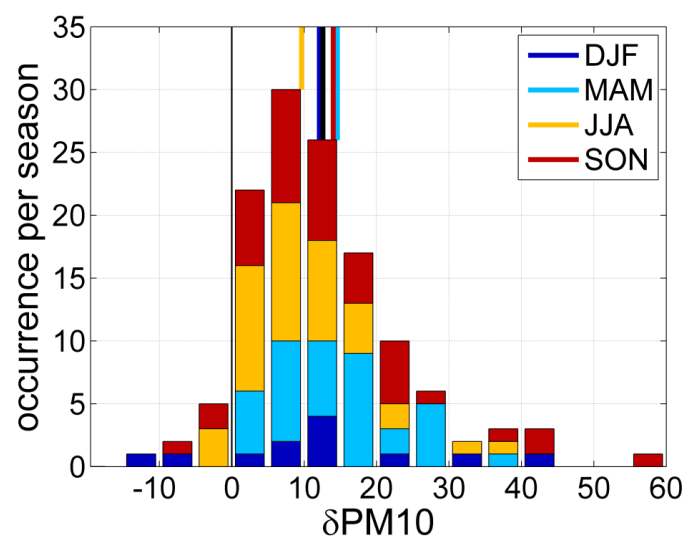

Fig. 3. Seasonal frequency distribution of all $\mathrm{PM}_{10}$ changes associated to Saharan advections $(\delta \mathrm{PM})$ at the two Rome stations of MG and VA in the period 2001-2004. Colour thick lines at the top of the plots specify the seasonal average, the black one representing the yearly average.

\section{Conclusions}

A four-year (2001-2004) database of $\mathrm{PM}_{10}$ mass concentrations, together with modelled and observed Saharan dust advection events have been used to evaluate the impact of Saharan dust on the $\mathrm{PM}_{10}$ mass concentrations in the city of Rome, Italy. In this period, BSC-DREAM8b model forecasts and Lidar observations indicate that advection of Saharan dust crossed over Rome on $26 \%$ and $29 \%$ of the days, respectively. These events occurred mostly between March and November. Advection to the ground, possibly affecting the $\mathrm{PM}_{10}$ concentrations, was evaluated to take place on 13 and $18 \%$ of the days, respectively.

Analysis of the meteorological parameters and of $\mathrm{PM}_{10}$ loads accompanying Saharan advections to the Rome region showed that the best averaging period over which to define the "background" $\mathrm{PM}_{10}$ level is represented by the 7 days preceding the event rather than the \pm 15 days suggested by the current EU Guidelines (EC, 2011). However, for the regional background station of Fontechiari, use of the two averaging methods brings to estimates of the impact of dust within $20 \%$ from each other $\left(9.2\right.$ vs. $10.8 \mu \mathrm{g} \mathrm{m}^{-3}$, respectively).

Between 25 and $30 \%$ of the city yearly exceedances of the daily $50 \mathrm{\mu g} \mathrm{m}^{-3}$ limit were found to be associated to Saharan advections. On a year basis, such advections caused a $\mathrm{PM}_{10}$ increase of the order of $2.35 \mathrm{\mu g} \mathrm{m}^{-3}$. Even though subtracting the "Saharan" exceedances (28) is not sufficient to reduce the yearly number of exceedances of the MG traffic station (107) below the EU mandatory limit of 35, subtraction of the mass contribution may be sufficient at lowering the year average $\mathrm{PM}_{10}\left(43.85 \mu \mathrm{g} \mathrm{m}^{-3}\right)$ close to the EU limit of $40 \mu \mathrm{g} \mathrm{m}^{-3}$.
Statistics of Lidar-estimated dust mass concentrations (retrievals based on extinction-to-mass conversion factors reported in Barnaba and Gobbi, 2004), resulted to be in very good agreement with the (ground-based) $\mathrm{PM}_{10}$ statistics when considering a typical $\mathrm{PM}_{10} / \mathrm{TSP}$ ratio of 0.5 , as reported for Saharan advections in Barcelona by Querol et al. (2001). Furthermore, it was shown that a better assessment of transport events as allowed by the polarization Lidar measurements tends to increase the amount of $\mathrm{PM}_{10}$ attributable to the Saharan advection, avoiding the retrieval of negative $\mathrm{PM}_{10}$ changes observed when employing model forecasts alone. In this respect, the choice of the reference averaging period and accounting for meteorology (in particular rainy days) were shown to be central steps for the good assessment of advected dust loads.

The study also indicated that the altitude and time matching between the model forecasts and the Lidar observations are rather good. In fact, Lidar observations require model analysis to infer sources of the observed aerosols. At the same time, model forecasts require observations to confirm the actual presence of dust at the location under study. Therefore, synergy between the two techniques is demonstrated to be very important to correctly assess the contribution of this natural aerosol to PM levels.

Main results of this work were obtained by means of a research-type polarization Lidar coupled with $\mathrm{PM}_{10}$ observations and BSC-DREAM $8 \mathrm{~b}$ model forecasts. This approach is at the core of the EC LIFE +2010 project "DIAPASON" (www.diapason-life.eu) aimed at demonstrating the benefit of automated, polarization Lidar-Ceilometers, partly developed within the project, at proving the effects of Saharan dust advections (and more in general of long-range aerosol advections) on European PM loads.

Acknowledgements. This work was partly supported by the EU LIFE+2010, DIAPASON project (ENV/IT/391). J. M. Baldasano and S. Basart acknowledge the CICYT project (CGL2010-19652), the "Supercomputación and e-ciencia" project (CSD20070050) from the Consolider-Ingenio 2010 program and Severo Ochoa (SEV-2011-00067) program of the Spanish Goverment. NMMB/BSC-Dust simulations were performed on the Mare Nostrum supercomputer hosted by Barcelona Supercomputing Center-Centro Nacional de Supercomputación (BSC-CNS). We thank P. Kishcha, and the other two anonymous referees for their constructive reviewing of the manuscript.

Edited by: Y.-S. Chung 


\section{References}

Amiridis, V., Kafatos, M., Perez, C., Kazadzis, S., Gerasopoulos, E., Mamouri, R. E., Papayannis, A., Kokkalis, P., Giannakaki, E., Basart, S., Daglis, I., and Zerefos, C.: The potential of the synergistic use of passive and active remote sensing measurements for the validation of a regional dust model, Ann. Geophys., 27, 3155-3164, doi:10.5194/angeo-27-3155-2009, 2009.

Barnaba, F. and Gobbi, G. P.: Aerosol seasonal variability over the Mediterranean region and relative impact of maritime, continental and Saharan dust particles over the basin from MODIS data in the year 2001, Atmos. Chem. Phys., 4, 2367-2391, doi:10.5194/acp-4-2367-2004, 2004.

Barnaba, F., Gobbi, G. P., and De Leuuw, G.: Aerosol stratification, optical properties and radiative forcing in Venice (Italy) during ADRIEX, Q. J. Roy. Meteorol. Soc., 133, 47-60, 2007.

Basart, S., Pérez, C., Cuevas, E., Baldasano, J. M., and Gobbi, G. P.: Aerosol characterisation in Northern Africa, Northeastern Atlantic, Mediterranean Basin and Middle East from direct-sun AERONET observations, Atmos. Chem. Phys., 9, 8265-8282, doi:10.5194/acp-9-8265-2009, 2009.

Basart, S., Pay, M. T., Jorba, O., Pérez, C., Jiménez-Guerrero, P., Schulz, M., and Baldasano, J. M.: Aerosols in the CALIOPE air quality modelling system: evaluation and analysis of PM levels, optical depths and chemical composition over Europe, Atmos. Chem. Phys., 12, 3363-3392, doi:10.5194/acp-12-33632012, 2012a.

Basart, S., Pérez, C., Nickovic, S., Cuevas, E., and Baldasano, J. M.: Development and evaluation of the BSCDREAM8b dust regional model over Northern Africa, the Mediterranean and the Middle East, Tellus B, 64, 18539, doi:10.3402/tellusb.v64i0.18539, 2012b.

Carnevale, C., Finzi, G., Pisoni, E., Volta, M., Kishcha, P., and Alpert, P.: Integrating Saharan dust forecasts into a regional chemical transport model: a case study over Northern Italy, Sci. Total Environ., 417-418, 224-231, 2012.

D'Almeida, G. A.: On the variability of desert aerosol radiative characteristics, J. Geophys. Res., 92, 3017-3026, 1987.

EC, 2008: EU Air Quality Directive 2008/50/EC, 2008.

EC, 2011: Commission Staff Working Paper: establishing guidelines for demonstration and subtraction of exceedances attributable to natural sources under the Directive 2008/50/EC on ambient air quality and cleaner air for Europe, SEC(2011) 208 final, 2011.

Escudero, M., Querol, X., Pey, J., Alastuey, A., Pérez, N., Ferreira, F., Alonso, S., Rodríguez, S., and Cuevas, E.: A methodology for the quantification of the net African dust load in air quality monitoring networks, Atmos. Environ., 41, 5516-5524, 2007.

Gobbi, G. P., Barnaba, F., Giorgi, R., and Santacasa, A.: Altituderesolved properties of a Saharan dust event over the Mediterranean, Atmos. Environ., 34, 5119-5127, 2000.

Gobbi, G. P., Barnaba, F., and Ammannato, L.: The vertical distribution of aerosols, Saharan dust and cirrus clouds in Rome (Italy) in the year 2001, Atmos. Chem. Phys., 4, 351-359, doi:10.5194/acp-4-351-2004, 2004a.

Gobbi, G. P., Barnaba, F., and Ammannato, L.: Lidar and photometric measurements of Saharan dust outbreaks at Izana (Tenerife) during the Minatroc 2002 field campaign, Reviewed and Revised Proceedings of the International Laser Radar Conference (ILRC22), edited by: Pappalardo, G. and Amodeo, A., European
Space Agency, SP-561, 369-372, 2004b.

Gobbi, G. P., Barnaba, F., and Ammannato, L.: Estimating the impact of Saharan dust on the year $2001 \mathrm{PM}_{10}$ record of Rome, Italy, Atmos. Environ., 41, 261-275, 2007.

Haustein, K., Pérez, C., Baldasano, J. M., Müller, D., Tesche, M., Schladitz, A., Esselborn, M., Weinzierl, B., Kandler, K., and Hoyningen-Huene, W. v.: Regional dust model performance during SAMUM 2006, J. Geophys. Res. Lett., 36, L03812, doi:10.1029/2008GL036463, 2009.

Highwood, E. J., Haywood, J. M., Coe, H., Cook, J., Osborne, S., Williams, P., Crosier, J., Formenti, P., McQuaid, J., Brooks, B., Thomas, G., Grainger, R., Barnaba, F., Gobbi, G. P., and De Leeuw, G.: Aerosol Direct Radiative Impact Experiment (ADRIEX) Overview, Q. J. Roy. Meteorol. Soc., 133, 3-15, 2007.

Kishcha, P., Alpert, P., Shtivelman, A., Krichak, S. O., Joseph, J. H., Kallos, G., Katsafados, P., Spyrou, C., Gobbi, G. P., Barnaba, F., Nickovic, S., Perez, C., and Baldasano, J. M.: Forecast errors in dust vertical distributions over Rome (Italy): Multiple particle size representation and cloud contributions, J. Geophys. Res., 112, D15205, doi:10.1029/2006JD007427, 2007.

Mallone, S., Stafoggia, M., Faustini, A., Gobbi, G. P., Marconi, A., and Forastiere, F.: Saharan Dust and Associations between Particulate Matter and Daily Mortality in Rome, Italy, Environ. Health Perspect., 119, 1409-1414, 2011.

Marinou, E., Amiridis, V., Tsekeri, A., Basart, S., Baldasano, J. M., Kazadzis, S., and Papayannis, A.: Comparison of Averaged extinction profiles from CALIPSO and BSC-DREAM8b dust model over Greece, International Laser Radar Conference (ILRC) Porto Heli (Greece), June 2012.

Mitsakou, C., Kallos, G., Papantoniou, N., Spyrou, C., Solomos, S., Astitha, M., and Housiadas, C.: Saharan dust levels in Greece and received inhalation doses, Atmos. Chem. Phys., 8, 7181-7192, doi:10.5194/acp-8-7181-2008, 2008.

Mol, W., van Hooydonk, P., and de Leeuw, F.: The state of the air quality in 2009 and the European exchange of monitoring information in 2010, ETC/ACM Technical Paper 1/2011, 2011.

Moulin, C., Lambert, C. E., Dayan, U., Masson, V., Ramonet, M., Bousquet, P., Legrand, M., Balkanski, Y. J., Guelle, W., Marticorena, B., Bergametti, G., and Dulac, F.: Satellite climatology of African dust transport in the Mediterranean atmosphere, J. Geophys. Res., 103, 13137-13144, 1998.

Nava, S., Becagli, S., Calzolai, G., Chiari, M., Lucarelli, F., Prati, P., Traversi, R., Udisti, R., Valli, G., and Vecchi, R.: Saharan dust impact in central Italy: An overview on three years elemental data records, Atmos. Environ., 60, 444-452, 2012.

Nickovic, S., Kallos, G., Papadopoulos, A., and Kakaliagou, O.: A model for prediction of desert dust cycle in the atmosphere, J. Geophys. Res., 106, 18113-18129, doi:10.1029/2000JD900794, 2001.

Papanastasiou, D. K., Poupkou, A., Katragkou, E., Amiridis, V., Melas, D., Mihalopoulos, N., Basart, S., Pérez, C., and Baldasano, J. M.: An Assessment of the Efficiency of Dust Regional Modelling to Predict Saharan Dust Transport Episodes, Adv. Meteorol., 2010, 154368, doi:10.1155/2010/154368, 2010.

Pay, M. T., Jiménez-Guerrero, P., Jorba, O., Basart, S., Querol, X., Pandolfi, M., and Baldasano, J. M.: Spatio-temporal variability of concentrations and speciation of particulate matter across Spain in the CALIOPE modeling system, Atmos. Environ., 46, 376- 
396, 2012.

Pérez, C., Nickovic, S., Baldasano, J. M., Sicard, M., Rocadenbosch, F., and Cachorro, V. E.: A long Saharan dust event over the western Mediterranean: Lidar, Sun photometer observations, and regional dust modeling, J. Geophys. Res., 111, D15214, doi:10.1029/2005JD006579, 2006a.

Pérez, C., Nickovic, S., Pejanovic, G., Baldasano, J. M., and Ozsoy, E.: Interactive dust-radiation modeling: A step to improve weather forecasts, J. Geophys. Res., 11, D16206, doi:10.1029/2005JD006717, 2006b.

Perrino, C., Canepari, S., Catrambone, M., Dalla Torre, S., Rantica, E., and Sargolini, T.: Influence of natural events on the concentration and composition of atmospheric particulate matter, Atmos. Environ., 43, 4766, doi:10.1016/j.atmosenv.2008.06.035, 2009.

Pey, J., Querol, X., Alastuey, A., Forastiere, F., and Stafoggia, M.: African dust outbreaks over the Mediterranean Basin during 2001-2011: $\mathrm{PM}_{10}$ concentrations, phenomenology and trends, and its relation with synoptic and mesoscale meteorology, Atmos. Chem. Phys., 13, 1395-1410, doi:10.5194/acp-13-13952013, 2013.

Putaud, J.-P., Raes, F., Van Dingenen, R., Brüggemann, E., Facchini, M.-C., Decesari, S., Fuzzi, S., Gehrig, R., Hüglin, C., Laj, P., Lorbeer, G., Maenhaut, W., Mihalopoulos, N., Müller, K., Querol, X., Rodriguez, S., Schneider, J., Spindler, G., ten Brink, H., Tørseth, K., and Wiedensohler, A.: A European aerosol phenomenology - 2: Chemical characteristics of particulate matter at kerbside, urban, rural and background sites in Europe, Atmos. Environ., 38, 2579-2595, 2004.

Querol, X., Alastuey, A., Rodriguez, S., Plana, F., Ruiz, C. R., Cots, N., Massagué, G., and Puig, O.: $\mathrm{PM}_{10}$ and $\mathrm{PM}_{2.5}$ source apportionment in the Barcelona Metropolitan area, Catalonia, Spain, Atmos. Environ., 35, 6407-6419, 2001.
Querol, X., Alastuey, A., Pey, J., Cusack, M., Pérez, N., Mihalopoulos, N., Theodosi, C., Gerasopoulos, E., Kubilay, N., and Koçak, M.: Variability in regional background aerosols within the Mediterranean, Atmos. Chem. Phys., 9, 4575-4591, doi:10.5194/acp-9-4575-2009, 2009a.

Querol, X., Alastuey, A., Pey, J., Pandolfi, M., Cusack, M., Perez, N., Viana, M., Moreno, T., Mihalopoulos, N., Kallos, G., and Kleanthous, S.: African dust contributions to mean ambient $\mathrm{PM}_{10}$ mass-levels across the Mediterranean Basin, Atmos. Environ., 43, 4266-4277, 2009b.

Rodriguez, S., Querol, X., Alastuey, A., Kallos, G., and Kakaliagou, O.: Atmospheric Saharan dust contributions to $\mathrm{PM}_{10}$ and TSP levels in Southern and Eastern Spain, Atmos. Environ., 35, 2433 2447, 2001.

Sakai, T., Nagai, T., Zaizen, Y., and Mano, Y.: Backscattering linear depolarization ratio measurements of mineral, sea-salt, and ammonium sulfate particles simulated in a laboratory chamber, Appl. Opt., 49, 4441, doi:10.1364/AO.49.004441, 2010.

Tafuro, A. M., Barnaba, F., De Tomasi, F., Perrone, M. R., and Gobbi, G. P.: Saharan Dust Particle Properties over the Central Mediterranean, Atmos. Res., 81, 67-93, 2006.

Tegen, I. and Lacis, A. A.: Modeling of particle size distribution and its influence on the radiative properties of mineral dust aerosol, J. Geophys. Res., 101, 19237-19244, 1996.

Yttri, K. E. and Aas, W. (Eds.): Trans-boundary Particulate Matter in Europe: Status Report 2006, EMEP Report, 4, 2006. 